\title{
CURADORIA DIGITAL: PAPÉIS E RESPONSABILIDADES DO ARQUIVISTA
}

\author{
CURADORA DIGITAL: PAPELES Y \\ RESPONSABILIDADES DEL ARCHIVISTA
}

\author{
Renata Oliveira de Araujo* \\ Márcio da Silva Finamor**
}

\begin{abstract}
RESUMO:
Introdução: Este artigo mostra os papéis e responsabilidades do arquivista no contexto da curadoria digital, verificando como o profissional a partir do uso de teorias, das tecnologias, instrumentos, processos e políticas, pode atuar e delinear ações e procedimentos estratégicos para os processos de curadoria e preservação digital.

Objetivo: Investigar quais os papéis e responsabilidades dos profissionais no contexto da curadoria digital para a preservação de dados ou preservação digital.

Metodologia: Revisão de literatura sobre o profissional arquivista, suas funções e atividades nas organizações no contexto da curadoria digital.

Resultados: Considerando a necessidade de atuação do arquivista e políticas sobre os documentos digitais e sua preservação a longo prazo. Em busca de ampliar e amadurecer concepções teóricas e práticas acerca da questão. $\mathrm{O}$ arquivista com 0 olhar acurado busca modificar ideias, pensamentos e teorias sobre a gestão da preservação e a ampliação da sua importância, principalmente a guarda e o acesso futuro dos documentos digitais. Por isso a importância da incorporação de profissionais qualificados e preparados aos quadros coorporativos das instituições, em que pode proporcionar às ações estratégicas de preservação.

Conclusões: Conclui que as perspectivas de atuação do arquivista são possíveis no desempenho da curadoria digital. De acordo com a existência de novas pesquisas e ensinamentos. A formação contempla aspectos teóricos, práticos, técnico e gestão sendo necessário investigar sobre a curadoria digital. Refletir profundamente sobre a sua formação quanto sua atuação no mercado de trabalho e persuasivo no seu fazer Arquivístico tanto digital quanto físico.
\end{abstract}

Palavras-chave: Arquivista. Curadoria Digital. Preservação digital. Documento digital. Curador da informação.

\section{INTRODUÇÃO}

Este artigo mostra os papéis e responsabilidades do profissional arquivista em atuação aos processos de curadoria digital. A saber como esse *Especialista em Gestão Eletrônica de Documentos - GED. Arquivista - UFF. E-mail: araujo.renatade@gmail.com **Mestre em Ciência da Informação. E-mail: marciofinamor@gmail.com 
profissional pode pensar em suas ações: teóricas, práticas e de gestão relacionadas a tal processo, uma vez que, tais iniciativas e ações requerem grandes desafios como será esclarecido.

Especialmente no contexto das tecnologias e globalização onde modificou as redes de comunicação e sua complexidade nas relações sociais, nos desenvolvimentos das organizações e empresas e no trabalho do dia a dia. Característica inerente dos dias atuais, na qual o trâmite informacional acontece de forma bastante acentuada, especialmente ao serem considerados os diversos recursos tecnológicos, faz-se necessário ponderar como tais tecnologias impactam no modo de se fazer e pensar. Desafios inerentes aos profissionais da informação e profissionais em geral.

Com essas novas opções tecnológicas, várias áreas do conhecimento adaptaram-se às novas ofertas da plataforma tecnológica considerando o contexto imposto pelas relações sociais, políticas e econômicas cada vez mais complexas e integradas. Profissionais como bibliotecários, arquivistas, museólogos, cientistas da informação, pesquisadores dentre outros, depararam-se com a necessidade de compreender as novas possibilidades advindas destas novas ferramentas tecnológicas e se enquadrar de alguma forma dentro desse novo modo através de uma revisão/concepção de um novo arcabouço teórico das áreas e inserção das atuais demandas informacionais e de ações empregadas para a sua preservação.

Sobre esse olhar que pretendo discutir ao longo desse trabalho. Como questões de seus papéis e responsabilidades do arquivista no contexto da curadoria digital para a preservação digital, verificando como o arquivista a partir do uso das tecnologias, instrumentos, processos e políticas, pode atuar e delinear ações e procedimentos estratégicos para a preservação digital.

\section{BREVE PANORAMA DA CURADORIA DIGITAL}

A criação das chamadas Tecnologias da Informação, após a $2^{\underline{a}}$ Guerra Mundial, foi um dos grandes marcos do século XX, modificando toda a forma de se pensar e trabalhar. Tal transformação influenciou profundamente diferentes áreas de atuação do homem e sobretudo dos profissionais que desenvolvem suas atividades cotidianas na acumulação, produção, uso e 
disseminação de informações de natureza diversa. De forma especial, aqueles que trabalham com os arquivos digitais, se deparam com documentos de "novo tipo", produzidos em meio digital e cujo suporte e formas de produção se diferenciam substancialmente em relação aos suportes convencionais existentes. como:

Nesse novo cenário, surgiu o conceito de curadoria compreende-se [...] o conjunto de ações que garantem que um conjunto de dados é genuíno, permitindo o seu uso por outros que não os seus produtores. A curadoria pode envolver ações de descrição dos dados, de ligação destes a outros que os tornem inteligíveis, de registo dos usos que tenham e dos resultados a que tenham dado origem. (FERREIRA et al., 2012, p. 26).

Os dados e informações digitais gerados pelas atividades de pesquisa; de bibliotecas digitais; instituições e organizações dentre outros, necessitam de cuidados específicos, tornando-se necessário a criação de novos modelos de custódia e de gestão de conteúdos científicos digitais que incluam ações de arquivamento seguro, preservação, formas de acrescentar valor a esses conteúdos e de otimização da sua capacidade de reuso. No intuito de colocar em prática soluções para o problema, observa-se, no âmbito de várias disciplinas, e de profissionais um esforço em torno do desenvolvimento de repositórios digitais orientados especialmente para uma gestão ativa de dados de pesquisa. É nesse ambiente que surge o conceito de curadoria digital de dados científicos, cujo principal desafio recai na necessidade de se preservar não somente o conjunto de dados, mas de preservar, sobretudo, a capacidade que ele possui de transmitir conhecimento para uso futuro das comunidades interessadas. Isto significa que os ativos genuínos da pesquisa científica ou outros dados, devem permitir que futuros usuários reanalisem os dados dentro de novos contextos. Porém, para que ocorra um processo de preservação em que os significados dos dados possam atravessar a barreira do tempo, é necessário assegurar que os usuários no futuro estejam instrumentados com as informações essenciais para o efetivo reuso dos dados (SAYÃO; SALES, 2012, p. 180). Para assegurar o acesso a esses dados presente e futuro, é preciso profissionais capacitados em seus respectivos papéis e responsabilidades, no uso de tecnologias, instrumentos adequados e políticas informacionais dentre outros. 
De fato, o fazer pensar e repensar no que tange as ações de preservação é ponto crucial para a sobrevivência das informações e de dados. Dessa forma, curadoria digital é o processo de ações e medidas para a segurança e preservação de dados. Sendo o resultante de iniciativas internacionais para preservação da informação científica; da criação de uma infraestrutura para que pudesse aportar a chamada ciência digital - nos Estados Unidos a chamada ciberinfraestrutura e no Reino Unido, de E-science.

O termo "curadoria" foi transposto de museus e bibliotecas às mídias interativas (a Web e seus novos canais de comunicação). A curadoria digital diz respeito à gestão ativa de dados durante o tempo que ele continua a ser acadêmico, científico, de pesquisa, de administração e/ ou de interesse pessoal com os objetivos de apoiar sua reprodutibilidade, reutilização e agregando valor a esses dados, gerenciando-os do momento de sua criação até que eles sejam determinados como não úteis e garantindo a sua acessibilidade a longo prazo, assim como a sua preservação, autenticidade e integridade (HARVEY, 2010, p. 8, tradução nossa).

De acordo com Sayão e Sales (2012, p. 179) uma parte considerável dos resultados das atividades de pesquisa está sendo criada em formatos digitais, como por exemplo, a Ciência aberta. Embora de grande valor, esses dados estão sob o risco de serem perdidos pela obsolescência tecnológica e pela fragilidade inerente das mídias digitais. Dessa forma, a gestão de dados de pesquisa num ambiente distribuído e em rede se torna um desafio crescente para o mundo da pesquisa, para a Ciência da Informação e para a Preservação de Acervos de Ciência e Tecnologia. Como resposta a esse desafio surge 0 conceito de curadoria digital, que envolve a gestão de dados de pesquisa desde o seu planejamento, assegurando a sua preservação por longo prazo, descoberta, interpretação e reuso, seja no presente ou no futuro.

Um exemplo clássico deste conjunto é destacado pelo especialista em Gestão e Preservação de Documentos Arquivísticos Digitais Carlos Ditadi, em que relata no período de 1918 a 1919 a gripe espanhola se espalhou pelo mundo inteiro, matando de 20 a 80 milhões de pessoas. De origem viral, não havia tratamento conhecido. Como veio se extinguiu. Com o intuito de pesquisar meios de evitar uma nova catástrofe, a comunidade internacional das 
áreas médica e de saúde pública procurou por décadas algum vestígio biológico do vírus causador dessa enfermidade. Só depois de muito tempo, foi encontrada uma amostra de tecido humano infectado pelo vírus num hospital militar da Inglaterra. A partir desses vestígios estão sendo desenvolvidas pesquisas para se descobrir vacinas e meios de tratamento da gripe espanhola. As pesquisas em torno da amostra só se tornaram possíveis graças à preservação dos arquivos científicos, datados de 1916, daquele hospital militar (DITADI, 2003 apud SAYÃO, SALES, 2012).

Curadoria de dados de pesquisa: é a contribuição para o estabelecimento de um modelo de curadoria digital no país. Ela emerge como uma nova área de práticas e de pesquisa de espectro amplo que dialoga com várias disciplinas e muitos gêneros de profissionais. Assegura a sustentabilidade dos dados para o futuro, não deixando, entretanto, de conferir valor imediato a eles para os seus criadores e para os seus usuários. Facilitam o acesso persistente a dados digitais confiáveis por meio da melhoria da qualidade desses dados, do seu contexto de pesquisa e da checagem de autenticidade. Dessa forma, contribui para assegurar a esses dados validade como registros arquivísticos, significando que eles podem ser usados no futuro como evidência legal. $O$ uso de padrões comuns entre diferentes conjuntos de dados, proporcionado pela curadoria digital, cria mais oportunidades de buscas transversais e de colaboração. O outro elemento básico desse modelo são as ações que devem ser tomadas no decorrer do processo de curadoria. Em três tipos como: ações para todo o ciclo de vida; ações sequenciais e ações ocasionais. Essas ações, para cada uma, existem uma lista de normas, para agir especificamente. Esse modelo permite uma visão coletiva sobre o conjunto de funções necessárias à curadoria e à preservação de dados de pesquisa. Além de definir papéis, responsabilidades e conceitos, ela explicita a infraestrutura de padronização e as tecnologias que devem ser implementadas (SAYÃO; SALES, 2012, p. 184-187, grifo nosso).

Sayão e Sales (2012, p. 184) afirmam que a curadoria digital é resultado do acúmulo dos conhecimentos e práticas em preservação e acesso a recursos digitais que resultaram num conjunto de estratégias, abordagens tecnológicas e atividades que agora são coletivamente conhecidas como "curadoria digital". 
Os autores apontam que, ainda que em evolução, o conceito envolve a gestão atuante durante todo o ciclo de vida de interesse do mundo acadêmico e científico, tendo como perspectiva o desafio atemporal de atender as gerações futuras de usuários, bem como, a preservação das informações correntes e futuras.

O Centro de Curadoria Digital estabelece que curadoria digital é capaz de envolver, manter, preservar e agregar valor aos dados ao longo do seu ciclo de vida. Pryor (2007, p. 136) considera que a curadoria digital pode ser um conjunto de ações necessárias para preservar dados digitais e outros materiais também digitais através de todo o seu ciclo de vida e indefinidamente para gerações atuais e futuras de usuários. Essas ações não incluem somente os processos de arquivamento e preservação digitais, mas, também, todo o processo que é essencial à criação de dados e seu gerenciamento, assim como a capacidade de anexar valores aos dados a fim de gerar novas fontes de informação e conhecimento.

Tal ciclo seria a conservação digital e a preservação de dados são processos em andamento, e investimento intelectual, de tempo e recursos adequados. Sendo necessário realizar ações para promover a conservação e preservação ao longo do ciclo de vida dos dados. Abaixo segue modelo do ciclo de vida:

Figura 1 - Modelo de Ciclo de Vida da Curadoria Digital do DCC

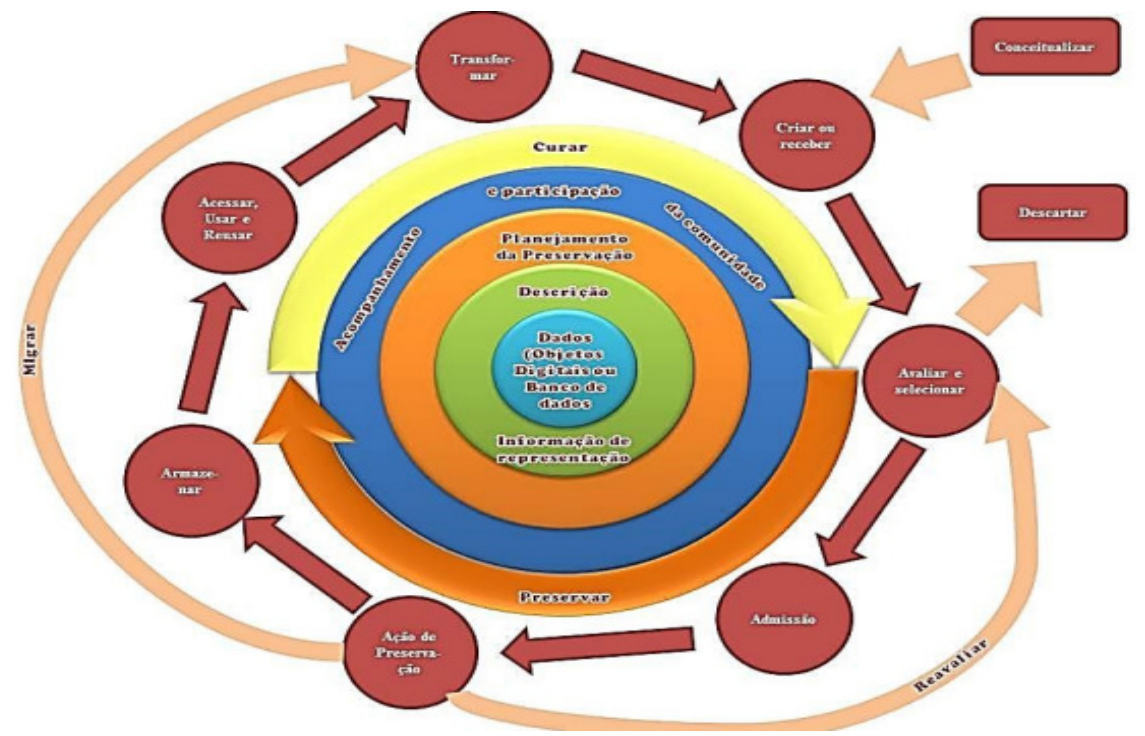

Fonte: Adaptado de (YAMAOKA, 2012). 
Esse modelo compreende quatro fases: dados, ações completas, ações sequencias e ações ocasionais e etapas como a conceitualização gerar e planejar a criação de objetos digitais, métodos de captura de dados e opções de armazenamento; criar, produzir objetos digitais e atribuir metadados arquivísticos administrativos, descritivos, estruturais e técnicos. A seguir as demais definições no quadro 1 :

Quadro 1 - Definições encontradas no sítio do Centro de Curadoria Digital Dados: qualquer informação em formato digital, estão no centro do ciclo de vida da curadoria. Objetos digitais: objetos digitais simples: arquivos de texto, imagem, som; ou objetos digitais complexos: site

Bancos de dados: estruturas de registros ou dados armazenados em um sistema. Ações Completas: descreve e representa a Informação conferi metadados administrativos, descritivos, técnicos, estruturais e de preservação, utilizando os padrões apropriados, para assegurar uma descrição e controle adequados a longo prazo. Recolhe e confere informações de representação para entender e compilar o material digital e os metadados.

Planejamento de preservação: planejar a preservar ao longo do ciclo de vida da curadoria digital. Determina planos de gerenciamento e administração de todas as ações do ciclo de vida da curadoria.

Comunidade: manter atividades comunitárias voltadas ao desenvolvimento de padrões compartilhados, ferramentas e softwares adequados.

Curadoria e preservação: esteja ciente e realize ações administrativas planejadas visando promover a conservação e preservação ao longo do ciclo de vida da curadoria.

Ações e sequencias: planejar a criação de dados, método de captura e as opções de armazenamento.

Criar ou receber: crie dados, metadados administrativos, descritivos, estruturais e técnicos. Os metadados de preservação também podem ser adicionados no momento da criação. Receber dados de acordo com política de coleta de documentos, repositórios, se necessário pode ser atribuído outros metadados

Avaliar e selecionar: avalie os dados e selecione para conservação a longo prazo. Aderir a orientações, políticas e requisitos legais.

Introduzir: transfira dados para um arquivo, repositório, centro de dados. Aderir a orientações, políticas ou requisitos legais.

Ação de preservação: realizar ações para garantir a preservação e retenção a longo prazo da natureza autorizada dos dados. As ações de preservação devem garantir que os dados permaneçam autênticos, confiáveis e utilizáveis, mantendo sua integridade. Incluem validação, atribuição de metadados de preservação, atribuição de informações de representação e garantia de estruturas de dados aceitáveis, formatos de arquivo.

Armazenar: armazene os dados de forma segura, respeitando os padrões relevantes. Acesso, Uso e Reutilização: certifique-se de que os dados sejam acessíveis aos usuários, no dia-a-dia. Isso pode ser na forma de informações públicas disponíveis. Podem ser aplicados controles robustos de acesso e procedimentos de autenticação.

Transformar: criar novos dados a partir do original,

Ações Ocasionais - Descarte: descarte dos dados, que não foram selecionados para conservação e preservação de longo prazo de acordo com políticas, orientação ou requisitos legais. Em geral os dados podem ser transferidos para outro arquivo, repositório, data center ou outro custodiante. Em alguns casos, os dados são destruídos. A natureza dos dados pode, por razões legais, exigir uma destruição segura.

Reavaliar: Retornar dados que falham nos procedimentos de validação para posterior avaliação e re-seleção.

Migrar: migre dados para um formato diferente. Isso pode ser feito de acordo com o ambiente de armazenamento ou para garantir a imunidade dos dados de obsolescência de hardware ou software.

Fonte: (DIGITAL CURATION CENTRE, 2014, tradução nossa) 
O mapa conceitual visa representar o conhecimento referente a curadoria digital, foi elaborado o mapa conceitual com o objetivo de revelar a visão geral da pesquisa conforme a figura abaixo:

Figura 2- Mapa conceitual da curadoria digital

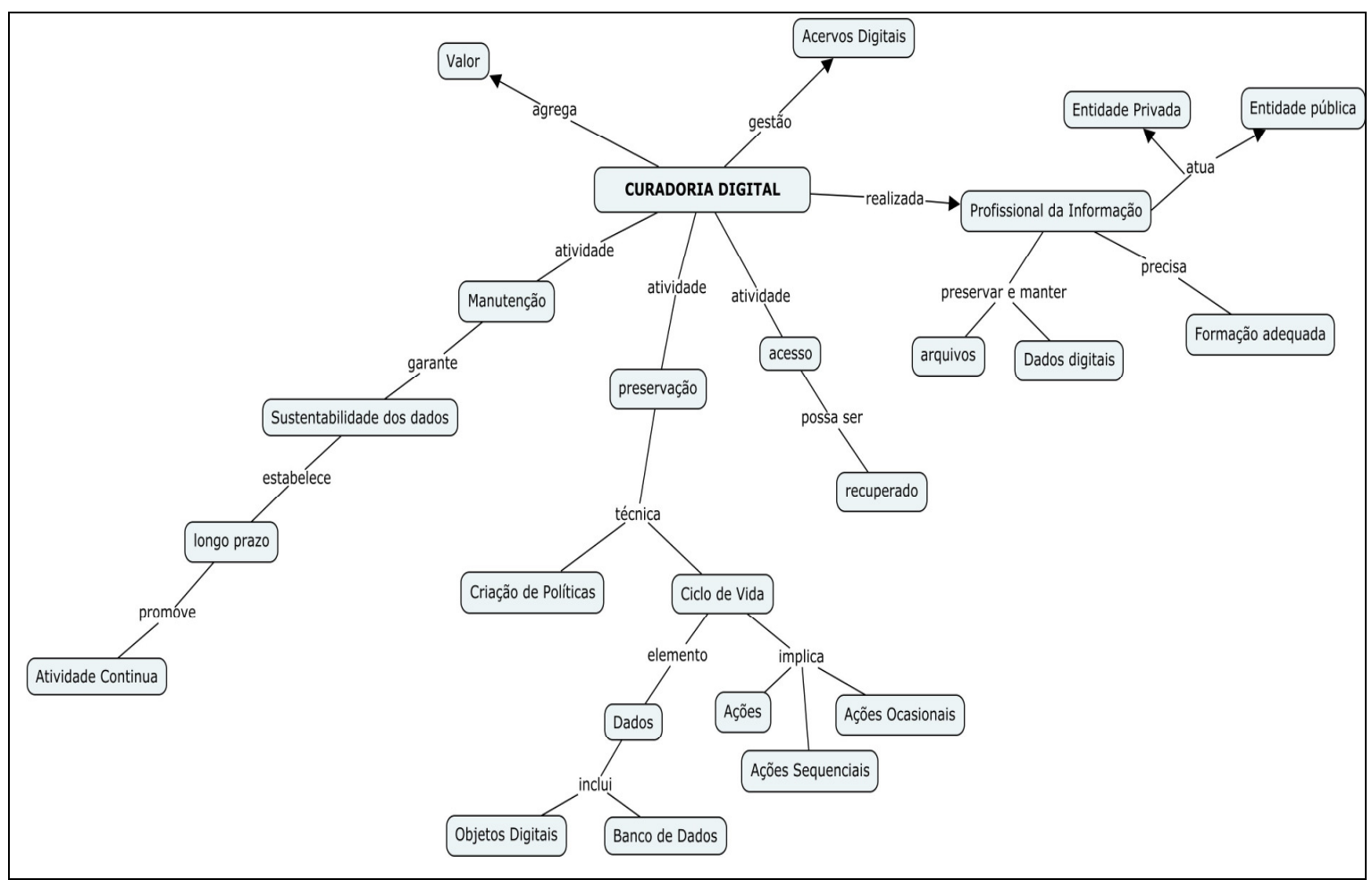

Fonte: os autores

A figura representa o pensamento exploratório sobre o tema como resultado da pesquisa: como o produto da análise dos conceitos expostos no artigo.

\section{O PROFISSIONAL ARQUIVISTA E A PRESERVAÇÃO DIGITAL}

O arquivista é o profissional que atua em órgãos públicos e empresas privadas com as atribuições de planejamento, implantação, organização e direção dos arquivos e sistemas arquivísticos; a gestão de documentos, o acompanhamento do processo documental e informativo; a identificação das espécies documentais; o planejamento de novos documentos e o controle de multicópias, arranjos, descrição, avaliação, conservação, preservação e restauração de documentos (quando necessário). Cabe ao profissional registrar, conservar e disseminar as informações produzidas no âmbito das atividades das instituições e organizações em geral tendo em vista a tomada 
de decisão para o desenvolvimento organizacional e processos legais sobre 0 gerenciamento da informação física e digital.

Tratar da preservação digital no âmbito da arquivística faz referência ao documento arquivístico digital. Para o e-ARQ Brasil ${ }^{1}$ (2006, p. 39) [...] nos documentos digitais, o foco da preservação é a manutenção do acesso, que pode implicar na mudança de suporte e formatos, bem como na atualização do ambiente tecnológico.

As técnicas de preservação incluem a prevenção da vida útil da tecnologia, emulação, encapsulamento, migração e preservação da tecnologia. Sendo recomendável adotar formato digital aberto como medida de preservação. Já o conselho Nacional de Arquivos - ICA não estabelece uma técnica de preservação [...] os aspectos práticos da preservação de documentos de arquivo eletrônicos. Qualquer técnica de preservação deve ser consistente com os requisitos essenciais de autenticidade, integralidade, acessibilidade e inteligibilidade, capacidade de processamento e potencial reutilização. A consideração destes requisitos não nos leva a sugerir uma técnica de preservação em particular como sendo a solução que os arquivos devem adoptar. Seria insensato fazê-lo, e muito menos numa altura em que as soluções continuam a evoluir rapidamente (Id, p. 54).

O Projeto InterPARES ${ }^{2}$ estabelece diretrizes de preservação digital visando orientar o preservador (instituições, organizações e preservadores individuais) dos documentos arquivísticos digitais objetivando a presunção [...] acurácia é o grau de precisão, correção, verdade e ausência de erros e distorções existente nos dados contidos nos materiais. Para assegurar a acurácia, deve-se exercer controle sobre os processos de produção, transmissão, manutenção e preservação dos materiais. Com o tempo, a responsabilidade pela acurácia é passada do autor para o responsável pela manutenção e, mais tarde, para o preservador em longo prazo dos documentos arquivísticos (se for aplicável) [...] e autenticidade refere-se ao fato de que os documentos arquivísticos são o que eles dizem ser e que não foram

\footnotetext{
${ }^{1}$ Modelo a ser seguido e de Requisitos para Sistemas Informatizados de Gestão Arquivística de Documentos.

${ }^{2}$ O Projeto InterPARES - International Research on Permanent Authentic Records in Electronic Systems (Pesquisa Internacional sobre Documentos Arquivísticos Autênticos Permanentes em Sistemas Eletrônicos.
} 
adulterados ou corrompidos de qualquer outra forma. Assim, com relação aos documentos arquivísticos em particular, a autenticidade refere-se à confiabilidade dos documentos enquanto tais. Para assegurar que a autenticidade possa ser presumida e mantida ao longo do tempo, deve-se definir e conservar a identidade dos documentos arquivísticos e proteger sua integridade. A autenticidade é colocada em risco sempre que os documentos arquivísticos são transmitidos através do tempo e do espaço. Ao longo do tempo, a responsabilidade pela autenticidade é passada do responsável pela manutenção para o preservador em longo prazo dos documentos arquivísticos (INTERPARES PROJECT, 2012, p. 23). O projeto consiste em três (3) etapas com o com o intuito de desenvolver conhecimento teórico e metodológico para a preservação digital de documentos arquivísticos gerados eletronicamente. Primeiro, formular modelos de estratégias, políticas e padrões capazes de assegurar a preservação. Nesse contexto, podemos destacar os modelos para elaboração de políticas para preservação digital que abarcam a captura do objeto digital, organização, trâmite, preservação e autenticidade.

A UNESCO considera a preservação digital como o conjunto de processos para garantir a continuidade do património digital durante todo 0 tempo considerado necessário, (UNESCO, 2002, p. 31, tradução nossa).

No Brasil, a Câmara Técnica de Documentos Eletrônicos do CONARQ trata da gestão e preservação de documentos eletrônicos, onde-se criou em 2004 a carta Carta de preservação do patrimônio arquivístico digital e, por meio da resolução de número (20) com o objetivo de ampliar a discussão em torno do documento eletrônico com vistas a estabelecer políticas e estratégias que garantam a preservação e o acesso dos documentos arquivísticos digitais.

Assegurando o uso padrão de preservação digital a norma ISO 19005-1 determina a utilização da extensão PDF/A para documentos arquivísticos digitais que necessitem de preservação por longo prazo. O padrão deriva do formato proprietário da Adobe Corporation em sua versão 1.4. Com isso, o Modelo OAIS (Open Archival Information System) define seis (6) entidades funcionais: recepção, armazenamento, gerenciamento de dados, administração do sistema, planejamento de preservação e acesso, que fazem parte do ciclo de informação. Como podemos verificar no modelo abaixo: 
Figura 3: Entidades Funcionais

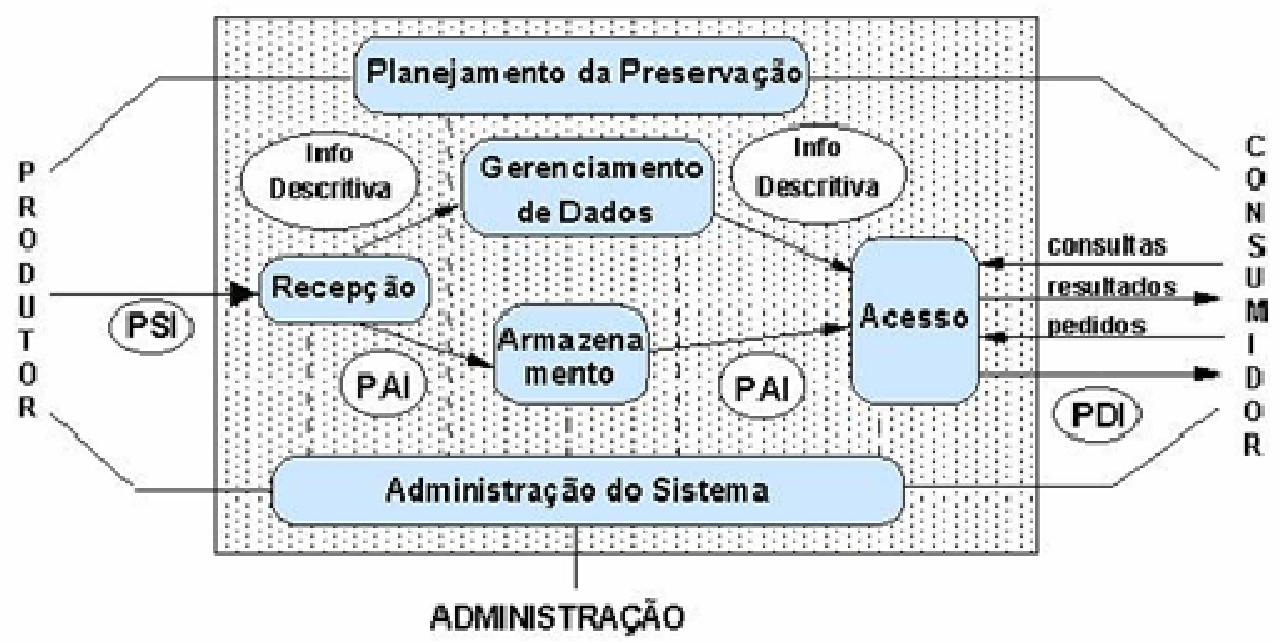

Fonte: (THOMAZ; SOARES, 2004, p. 16).

Esse modelo tem como objetivo preservação a longo prazo e acesso contínuo a informações digitais. Considerado um sistema aberto de arquivamento com aplicabilidade em preservação de documentos digitais.

Sobre a questão da preservação Hollós (2010, p. 27), ressalta que a preservação documental e (digital) deve ser entendida como uma atividade multidisciplinar. Para isso, a atualização de alguns conceitos e posturas relacionados à preservação, como a própria mudança de olhar do conservador: um olhar ampliado que busca a convergência de visão e valores, voltados a estratégias e ações integradas de preservação sistêmica. Isto é, a preservação, para além da conservação física dos suportes materiais, como parte de um corpo representado também pela gestão, o acesso e a difusão da informação e do conhecimento (HOLLÓS, 2010, p. 14). No caso dos documentos analógicos, preservação do suporte e sua forma física asseguram a conservação do conteúdo, porém, a mesma situação não se aplica a documentos digitais (WEITZEL; MESQUITA, 2015).

Uma vez que, os equipamentos e softwares utilizados são substituídos rapidamente por versões mais recentes e o risco da obsolescência é o grande inimigo ainda não dominado. A forma digital, embora aparentemente se mostre bastante atrativa, logo se torna obsoleta, exigindo uma preservação vigiada e permanente, com garantias de recursos materiais para as atualizações necessárias. A necessidade de elaboração de um "testamento", de uma política 
específica de preservação e acesso em que "selecione e nomeie, que transmita e preserve, que indique onde se encontram os tesouros e qual o seu valor", para contribuir para que o sentido e o desejo de preservação, imanente em cada um de nós, se transforme em algo real e positivo, e deixe de ser o espectro que atordoa e frustra a nós diante do fato de que todas as coisas criadas pelo ser humano estão sujeitas às mesmas circunstâncias e acasos que determinam a nossa existência: a perda de tudo que é perecível (HOLLÓS, 2010, p. 28-29).

Deparamo-nos com uma mudança de paradigma que implica reconhecer a conservação preventiva como um meio eficaz de ampliação das possibilidades da preservação documental. Esses documentos, nascidos digitais, constituem-se um desafio de preservação ainda maior. Afinal, grande parte da informação produzida nos dias atuais, em praticamente todas as áreas da atividade humana, será perdida e deixará de se constituir como lugar de memória, a menos que sejam desenvolvidos políticas e mecanismos de gestão e preservação para conservá-la às gerações futuras (HOLLÓS, 2010, p. 25).

Observa-se, por meio da literatura, que a preservação digital ainda é uma questão nova e suscita discussões acaloradas, mostra-se um ponto sensível à preservação dos conteúdos, conforme esse fato:

[...] pode ser responsável por práticas pobres, tais como o baixo índice do uso de extensões de arquivos de alta adequação de preservação digital e a falta de diversificação nas estratégias de preservação digital, privilegiando: backup; inclusão de metadados; e preservação da tecnologia. (WEITZEL; MESQUITA, 2015, p. 183).

É preciso pensar não só na preservação do suporte físico, mas também no seu acesso futuro. Das estratégias para a preservação digital hoje destacamos a preservação da tecnologia, emulação, migração, encapsulamento, metadatos, identificadores persistentes, backup, redes de distribuição de preservação digital, e de todos esses mecanismos o mais utilizado no Brasil ainda são os backups (WEITZEL; MESQUITA, 2015).

Sobre os aspectos da preservação digital (GRÁCIO, 2012, p. 74, grifo nosso) destaca bem sobre as questões que envolvem variadas ordens, como: tecnológicas, pois está inserida no ambiente digital, onde o objeto digital a ser preservado é descrito por suas características de hardware, software e suporte; 
relativa aos profissionais envolvidos nas atividades definidas pelas instituições; concernentes a todos os processos de gestão; legais que garantem o autor e à instituição a autenticidade do objeto digital e sua preservação por um longo período de tempo; econômicas, ou seja, os investimentos financeiros necessários para manter os processos de preservação, que devem ser permanentes; culturais, por envolver uma mudança de atitude e nas atividades das pessoas e dos grupos institucionais. Todas essas questões devem integrar a preservação física, lógica e intelectual dos objetos digitais a serem preservados e inserir-se nas políticas de preservação digital a ser definida pelas instituições. Não é suficiente armazenar um objeto digital no suporte adequado; é necessário pensar nos aspectos que permitem sua busca e recuperação no futuro, preservando-lhe também o conteúdo, a integridade e a autenticidade.

\section{PAPÉIS E RESPONSABILIDADES DO ARQUIVISTA NA CURADORIA DIGITAL}

O profissional Arquivista deve interagir efetivamente as demais disciplinas que lidam com o tratamento da informação de âmbito digital. Zelar pela documentação arquivística neste contexto da mesma forma que zela da documentação física. Atentando-se, para a preservação a longo prazo e acessibilidade contínua. Construindo uma área específica de preservação digital de cunho interdisciplinar com o intuito de interagir com as novas questões, instituir uma política de preservação digital. Atrelar a gestão de documentos a preservação digital, dentro do contexto da política arquivística da instituição.

O papel do arquivista na curadoria digital é o de um agente que deve construir pontes que atravessam disciplinas, funções de curadoria, níveis de hierarquia organizacional (linhas de trabalho, gerência, administração) em volta do ciclo de vida do objeto digital para assegurar a preservação em longo prazo do patrimônio cultural, científico e governamental. Estando esse profissional atrelado a equipe multiprofissional para juntos alinhar estratégias fundamentais para a preservação digital (TIBBO; LEE, 2012). 
O Observatório de Ciência da Informação da Universidade do Porto, o perfil do profissional da informação denominado curador digital tem como uma das formações a de Arquivista com a missão de preservar manter arquivos e dados digitais. Locais de ação entidades públicas ou privadas, com ou sem fins lucrativos. Deve atuar em gerir o processo de criação e desenvolvimento de repositório de dados para consultas posteriores realizadas por investigadores, cientistas, historiadores e profissionais da área. Como forma de potenciar as empresas na melhoria da qualidade de informação e dados quer nos seus processos operacionais, estratégicos e do desenvolvimento organizacional.

\section{Como as:}

Funções:

- Recolha de informação digital;

- $\quad$ Fornecimento de busca e recuperação de informação digital;

- $\quad$ Certificação de confiabilidade e integridade do conteúdo;

- $\quad$ Continuidade e comparabilidade semântica e ontológica do conteúdo;

- Conceitualização: concepção e planeamento de criação de conteúdo, incluindo a definição de métodos de captura e armazenamento;

- Criação: produção de conteúdo e atribuir característica administrativa, descritiva, estrutural e técnica aos dados.

- Garantir acesso e uso: garantia de fácil acesso à conteúdos públicos e privados pelos usuários;

- $\quad$ Avaliação e seleção: avaliação e seleção de conteúdos digitais que requerem preservação atendendo normas, processos e requisitos necessários para o procedimento.

- $\quad$ Disposição: se desfazer de conteúdo não selecionados para preservação, atendendo normas estabelecidas.

- $\quad$ Fazer Backup's: transferir conteúdo digital para um arquivo confiável e realizar o backup, atendendo normas estabelecidas.

- Preservação: ações que garantem a preservação e identificação do conteúdo;

- Reavaliação: avaliação e seleção adicional para conteúdo já avaliado;

- Armazenamento: manutenção dos dados de forma segura dentro dos padrões pré-definidos;

- $\quad$ Transformação: criação de novo conteúdo a partir do original.

O papel do curador é de administrar o fluxo de conteúdo digital, redes sociais ou outros sistemas de informação que organizam os dados de acordo com o perfil dos seus usuários, dessa forma passa a exercer o controlo sobre a informação a que o usuário pode aceder apresentando apenas um tipo específico de conteúdo.

Das Competências Profissionais - Informação:

- Relações com os utilizadores e Cliente;

- Compreensão do meio profissional; 
- $\quad$ Aplicação do direito de informação;

- Gestão dos conteúdos e conhecimentos;

- $\quad$ Identificação e validação das fontes de informação;

- $\quad$ Análise e representação da informação;

- $\quad$ Pesquisa de Informação;

- $\quad$ Gestão das coleções e fundos;

- $\quad$ Enriquecimento das coleções e fundos;

- $\quad$ Concepção de produtos e serviços.

Tecnologias:

- $\quad$ Concepção informática de sistemas de informação;

- Desenvolvimento informático de aplicações;

- $\quad$ Publicação e edição;

- Tecnologias da Internet;

- Tecnologias da informação e comunicação;

Comunicação:

- $\quad$ Comunicação escrita;

- $\quad$ Comunicação audiovisual;

- $\quad$ Comunicação pela informática;

- $\quad$ Prática de uma língua estrangeira;

- $\quad$ Comunicação interpessoal;

- Comunicação institucional.

Gestão (Management):

- $\quad$ Gestão Global da Informação;

- Diagnóstico e avaliação.

Das Aptidões Pessoais - Relacionamento:

- $\quad$ Autonomia;

- $\quad$ (Capacidade de) Comunicação;

- (Espírito de) Equipe.

-

Pesquisa:

- Espírito de Curiosidade;

Análise:

- $\quad$ (Espírito de) Análise;

- $\quad$ (Espírito) Crítico;

- $\quad$ (Espírito de) Síntese.

Comunicação:

- $\quad$ Capacidade de resposta.

Gestão: 
- Rigor.

Organização:

- $\quad$ Sentido de) Antecipação;

- $\quad$ Espírito de) Decisão;

- $\quad$ (Espírito de) Iniciativa;

- $\quad$ (Sentido de) Organização;

Essas listas de competências, funções e papéis tem como objetivo proferir ao profissional arquivista o passo inicial para ser um agente de curadoria digital. Em tempos que os ambientes organizacionais, empresariais e públicos os tomadores de decisão utilizam documentos sejam eles físicos e digitais para as tomadas de decisões, isto é, em informação registrada (qualquer formato). A informação arquivística é indispensável, sendo utilizada e necessária como aporte ao processo de tomada de decisão e ações das empresas e pessoas. O profissional arquivista nas organizações e instituições sua atuação com a rede de equipe multiprofissional é relevante por agir e atuar com informações e documentos (físicos e digitais) o que tange sua acessibilidade, conservação para o apoio a tomadas de decisão e cunho estratégico.

Moreno (2007, p.18-19) detecta-se que o que vem sendo denominado de informação estratégica pela literatura da área de Ciência da Informação e subáreas apresenta-se de natureza de informação arquivística. Está informação apresenta características especiais, com metodologias próprias para sua gestão, com legislação específica, entre outras. O que se verifica é o uso da informação arquivística (informação registrada em qualquer formato) na tomada de decisão. É onde o arquivista deve estar atento em todos esses processos de investigação na organização para a produção.

É dentro desse contexto, que profissionais da área e pesquisadores da Arquivologia, tem estudado novas formas de gerenciar e organizar esses documentos desde a sua produção até a sua eliminação seja ela em Instituição ou organização. Com metodologias, políticas e processamentos técnicos, aprimorando suas atividades no apoio ao crescimento organizacional e nas melhorias nos processos documentais. E acentuamos que os digitais não são 
diferentes e que devem ter o mesmo olhar atencioso e especial nessa era digital e virtual.

\title{
5 PESRPECTIVAS DE ATUAÇÃO DO ARQUIVISTA NA CURADORIA DIGITAL: UM OLHAR CRÍTICO
}

O advento das tecnologias cresce em ritmo acelerado, o que provocou o fascínio da sociedade, e desta forma, diversos setores incorporaram as ferramentas de tecnologias da informação a fim de executar suas atividades, seja profissional ou pessoal. Assim, observa-se que a rápida expansão para o meio digital ocorreu sem mensurar os possíveis impactos desencadeados pela tecnologia, colocando parte significativa da memória social em risco. Logo, grandes volumes de documentos digitais podem ser perdidos devido às falhas de planejamento e a insuficiência de conhecimentos sobre os efeitos da obsolescência tecnológica e a interoperabilidade (SANTOS; FLORES, 2015, p. 202).

\begin{abstract}
Pode-se dizer que o documento arquivístico digital está inserido em um cenário de incertezas, pois as ferramentas de tecnologias da informação facilitam a sua produção, entretanto, a sua preservação em longo prazo ainda é incerta e abstrata. Neste contexto, é preciso preservar os documentos produzidos no passado, produzidos na atualidade, e aqueles que serão produzidos no futuro, por meio de tecnologias ainda não conhecidas. Tais fatos agravam o problema, pois os documentos digitais estão se tornando cada vez mais complexos. Destaca-se que estes registros estão condicionados a um cenário no qual a tecnologia não vai parar de avançar, proporcionando novos softwares, novas versões, com mais recursos, e gerando maior diversidade de formatos de arquivo, o que agrava a complexidade e a especificidade dos documentos arquivísticos digitais (SANTOS; FLORES, 2015, p. 202).
\end{abstract}

Para os desafios da competitividade mercadológica, impõe-se o valor estratégico da ciência e do conhecimento. Dentre essas questões, uma que interessa sobremaneira trata da modernização e internacionalização do nosso modelo acadêmico, isto é, não basta mais garantir somente a boa formação aos estudantes e acesso as melhores tecnologias, é preciso desenvolver novas habilidades e competências exigidas pelos mais diversos campos de trabalho, altamente impactados pela demanda crescente por informação gerada pela explosão do universo digital e da sociedade em rede. Nesse contexto de 
mudanças cada vez mais dinâmicas, o conhecimento torna-se obsoleto rapidamente. No caso da Ciência da Informação, vanguarda em relação a muitos campos do saber científico-tecnológico, pode-se inferir que metade do aprendizado adquirido em tecnologia na Universidade estará superado após cinco anos. É preciso, então, pensar em uma qualificação holística e específica, além da valorização das habilidades de relação do social, comunicação, gestão, liderança, metodológicas, culturais, multidisciplinares e sistêmicas (PALETTA, 2016, p. 58-59).

Uma vez que a preservação de longo prazo requer a disponibilidade de recursos financeiros para então criar um ambiente seguro, no qual sejam implementados padrões de formatos, padrões de metadados, normas e estratégias operacionais. Paralelo a isto, há uma série de definições que devem ser consideradas, devendo-se ressaltar que o planejamento será fundamental para este trabalho de longo prazo tanto do profissional arquivista quanto de outros envolvidos. Inicialmente, devem-se definir as ações, e, paralelamente, verificar a disponibilidade de recursos para estas. Observa-se que este processo vai se repetir para qualquer etapa da preservação, podendo assim, estabelecer a seguinte consideração: o planejamento de longo prazo é a principal atividade no processo de preservação digital, através dele é possível identificar a viabilidade de garantir o acesso fidedigno aos documentos arquivísticos digitais. Logo, o planejamento da preservação deve estar associado ao planejamento organizacional, desta forma, a organização como um todo se envolverá com o processo de preservação. As políticas de preservação digital precisam de prioridade organizacional, assim, será possível delegar os investimentos necessários para desenvolver a infraestrutura ideal, resultando em um ambiente confiável para a preservação de documentos digitais em longo prazo segundos os autores (SANTOS; FLORES, 2015, p. 211).

A DigCurv (Digital Curator Vocational Education Europe Project), apoia o desenvolvimento profissional de curadores digitais. O Enquadramento Curricular DigCurV oferece um meio para identificar, avaliar e planejar treinamento para atender aos requisitos de habilidades do pessoal envolvido em curadoria digital, agora e no futuro. Profissional multidisciplinar que deve 
compreender as tecnologias de preservação digital, legislação de direitos autorais e padrões de metadados, ser capaz de planejar tarefas, se comunicar com diversos grupos e realizar avaliações de risco, conhecimento e princípios; aptidões e competências. Já para o DigCCurr (Instituto profissional de práticas de curadoria para o ciclo de vida do objeto digital, visando preservar o acesso por longo tempo e construir um currículo de curadoria digital internacional.), os requisitos/áreas: mandatos, valores e princípios; funções e competências; contexto profissional, disciplinar ou institucional/organizacional; tipologia dos recursos; conhecimentos prévios; etapas do ciclo de vida. O Arquivista tem que ter as competências funcionais na criação e edição de diversos tipos de objetos digitais; digitalização; criação de metadados; gestão de repositórios e implementação de estratégias e preservação. Para além disso, foram exigidos conhecimentos ao nível de: formatos, workflow de curadoria, princípio de gestão de dados, arquitetura de repositórios, tecnologia de pesquisa e recuperação, estratégias de preservação, aplicação dos direitos de autor, políticas de investigação e procedimentos relacionados com gestão de dados.

Decorrente dos avanços das tecnologias, o documento digital surge na Arquivologia e rapidamente ganha relevância em virtude do volume de dados que vem sendo produzidos pelas pessoas e principalmente pelas organizações modernas. Dentre estes, observa-se que há registros possuem um valor social, e se encontram em risco de perca em virtude da obsolescência tecnológica e ausência de práticas de preservação digital. Desta forma, a implementação de estratégias de preservação digital torna-se uma urgência, caso contrário, diversos registros serão perdidos e deixarão lacunas na memória social (SANTOS; FLORES, 2015, p. 212).

A preservação digital necessita de práticas para salvaguardar os acervos, no entanto é preciso estabelecer um corpus teórico para as estratégias, sejam elas estruturais ou operacionais. Vive-se em um contexto no qual é preciso implementar soluções de preservação, porém estas soluções precisam de uma base teórica, prática e de gerenciamento. Salienta-se que a prática sem auxílio da teoria é tão inútil quanto a teoria sem aplicação prática. Tal afirmação reforça que teorias devem vislumbrar a atividade prática, bem como a prática deve respeitar o que foi definido teoricamente a priori 
(SANTOS; FLORES, 2015, p. 212).

Com a exceção de bibliotecas, arquivos e centros de documentação e informação, pode-se dizer que as organizações de modo geral não estão habituadas a preservar documentos, sejam eles digitais ou analógicos. Neste contexto, os documentos digitais correm um sério risco com relação à preservação de longo prazo. Não há nenhum exagero em se afirmar que instituições tradicionalmente responsáveis pela preservação estão com dificuldades para se adaptar a realidade digital (SANTOS; FLORES, 2015, p. 201).

Desta forma, ressalto que a necessidade de contextualizar a preservação digital como um problema não apenas tecnológico, mas também social, pois a memória das sociedades contemporâneas está correndo risco de perecer. Logo é preciso que as instituições responsáveis pela guarda da memória se adaptem rapidamente a realidade digital promovendo o avanço na pesquisa e a capacitação técnica dos envolvidos nos processos (SANTOS; FLORES, 2015, p. 209).

\section{CONSIDERAÇÕES FINAIS}

O Arquivista além da sua formação deve aprimorar seu conhecimento com novas disciplinas relacionadas a tecnologia e processos no âmbito da curadoria digital. Tais disciplinas são desconhecidas ainda, mas podemos relacionar algumas de acordo com o que foi apresentado no artigo como: gestão de tecnologia da informação para profissionais da informação (teoria e prática), conceitos, fundamentos e teorias da curadoria digital, tecnologia para preservação digital, publicação digital, web semântica, ferramentas para trabalhar com dados no âmbito da curadoria digital - metadados - teoria e prática, Gestão de riscos. Com isso deve-se instigar os pesquisadores da Arquivologia a pensar em programas com novas disciplinas específicas para incluir nas Escolas de Arquivologia do Brasil dessa forma preparando o profissional arquivista para as novas demandas no trabalho arquivístico, trabalho esse emergente e impossível de evitar. 
Partindo da premissa de ser analisado sob o olhar da Arquivologia e das tecnologias buscando mostrar a importância de um gerenciamento correto de documentos produzidos em meio digital, sendo extremamente importante para a Ciência e para as ações das empresas e pessoas. Já que, tal meio ainda carece de certas metodologias e práticas, especialmente por se tratar de um ambiente volátil e que está sendo constantemente atualizado e substituído por tecnologias de armazenamento mais modernas. O que nos leva a repensar nas atividades e responsabilidades. No que diz respeito à preservação digital, que além de ser usada para dar continuidade em pesquisas futuras, também serve como registro documental da história da instituição, garantindo assim que a memória desta seja preservada, consultada e subsidiada para novas pesquisas; recuperação dos documentos de forma eficaz e sua preservação.

De acordo com 0 arcabouço teórico instigado nesse artigo as perspectivas de atuação do arquivista são promissoras no desempenho da curadoria digital. Cognoscível a demanda por novas pesquisas e ensinamentos. Algumas competências na sua formação já possuem, tanto do caminho teórico, prático, técnico e gestão tendo que se aprofundar sobre a curadoria digital. Ter um olhar crítico tanto sobre a sua formação quanto sua atuação no mercado de trabalho e persuasivo no seu fazer Arquivístico.

Novos desafios, responsabilidades e papéis para 0 profissional arquivista. $\mathrm{O}$ artigo tentou mostrar o básico da curadoria digital visando pensar nos seus papéis e responsabilidades tendo em vista as habilidades e competências que foram citadas no trabalho juntamente com as suas habilidades e competência já construída e apreendidas em sua formação. Esse assunto está sendo revisitado na Arquivologia, mas emergente no estado atual e necessário tanto para a Sociedade da Informação quanto para as organizações públicas, privadas e para o profissional da informação, no caso o arquivista, tendo como novo caminho de atuação e de estudos. Apoiar os processos documentais, tomada de decisão, no desenvolvimento organizacional esse processo compreende estratégias que faz com que a organização melhore o desemprenho dentro do processo de documentos físicos e digitais: curadoria digital é mais que o processo para a preservação digital ela é o olhar teórico e prático para o melhor desempenho organizacional 
e funcional no que tange documentos e informações em geral. É o que Digital Curation Centre (DCC) possui em seu lema: "porque boa pesquisa precisa de bons dados". E bons dados serão só acessados se preservados.

\section{REFERÊNCIAS}

CÂMARA TÉCNICA DE DOCUMENTOS ELETRÔNICOS. Glossário de Documentos Arquivísticos Digitais. CONARQ. 2004. Disponível em: $<$ http://www.documentoseletronicos.arquivonacional.gov.br/media/publicacoes/ glossar io/2004ctdeglossariov1substituido.pdf>. Acesso em: 10 jun. 2017.

CARVALHO, J., FERREIRA, M. \& RODRIGUES, E. Estado da arte em preservação digital, 2012. Disponível em: <em 8 de fevereiro, 2017, em http://repositorium.sdum.uminho.pt/handle/1822/17049>. Acesso em: 11 jun. 2017.

CONSELHO INTERNACIONAL DE ARQUIVOS. Comitê de arquivos correntes em ambiente electrônico. Documentos de arquivo electrônicos: manual para arquivistas. ICA, Estudo no 16. Disponível em:

$<$ http://www.adporto.pt/ficheiros_a_descarregar/ica_estudo16_pt_4.pdf>. Acesso em: 16 de ago. 2017.

CONWAY, P. Preservação no universo digital. Rio de Janeiro: Projeto Conservação Preventiva em Bibliotecas e Arquivos: Arquivo Nacional, 2001.

DIGITAL CURATION CENTRE. What is digital curation? Disponível em: <http://www.dcc.ac.uk/digital-curation/what-digital-curation>. Acesso em: 23 out. 2017.

. International Digital Curation Conference. Disponível em: < http://www.dcc.ac.uk/events/international-digital-curation-conference-idcc>. Acesso em 10 ago. 2017.

DIGITAL CURATOR VOCATIONAL EDUCATION EUROPE. Disponível em: < http://www.digcur-education.org/>. Acesso em 10 ago. 2017.

DITADI, C. Preservação de documentos eletrônicos. Rio de Janeiro: Arquivo Nacional/ CTDE, 2003.

FERREIRA, M. Introdução à preservação digital: conceitos, estratégias e actuais consensos, 2006. Disponível em http://repositorium.sdum.uminho.pt/handle/1822/5820>. Acesso em: 14 jun. 2017. 
GRÁCIO, J. C. A. Preservação digital da informação: um modelo processual para as instituições de ensino superior. São Paulo: Cultura Acadêmica, 2012.

Disponível

em:< https://www.fasul.edu.br/portal/app/webroot/files/links/redes/Preservacao_ digital_na_gestao_da_informacao-WEB_v2.pdf>. Acesso em: 05 jul. 2017.

HARVEY, R. Digital Curation: a how-to-do-it manual. New York: NealSchuman, 2010.

HOLLÓS, A. C. Fundamentos da preservação documental no Brasil. Revista Acervo, Rio de Janeiro, v. 23, no 2, p. 13-30, jul/dez 2010. Disponível em:<http://www.revistaacervo.an.gov.br/seer/index.php/info/article/view/8/6>. Acesso em: 22 jun. 2017.

INTERPARES PROJECT. A elaboração e a manutenção de materiais digitais: diretrizes para indivíduos, 2012. Disponível em:

http://www.interpares.org/ip2/display_file.cfm?doc=ip2_preserver_guidelines_b ooklet--portuguese.pdf. Acesso em: 10 set. 2017.

KUNDA, S.; ANDERSON-WILK, M. Community stories and institutional stewardship: digital curation's dual roles of story creation and resource preservation. Libraries and the Academy, 2011 (4), p.895-914, Disponível em: $<$ http://digitalcommons.wou.edu/cgi/viewcontent.cgi?article=1006\&context=fac pubs.>. Acesso em: 14 jun. 2017.

PALETTA, F. C. Acesso, apropriação e uso da informação na sociedade em rede: desafios na formação do profissional da informação. In: MODESTO, J. F. (Org.); PALETTA, F. C. (Org.). Tópicos para o Ensino de Biblioteconomia. 1. ed. São Paulo: Editora Livre Expressão, 2016. v. 1. p. 184. Disponível em: $<$ http://www3.eca.usp.br/sites/default/files/form/biblioteca/acervo/textos/002746 699.pdf>. Acesso em: 14 jun. 2017.

SAYÃO, L. F.; SALES, L. F. Dados de pesquisa: contribuição para o estabelecimento de um modelo de curadoria digital para o país. Instituto de engenharia nuclear. 2013. Disponível em:<http://carpedien.ien.gov.br:8080/bitstream/ien/646/1/DADOS\%20DE\%20P ESQUISA.pdf>. Acesso em: 28 jun. 2017.

. Curadoria Digital: um novo patamar para preservação de dados digitais de pesquisa. Inf. \& Soc.:Est., João Pessoa, v.22, n.3, p. 179-191, set./dez. 2012.Disponível em: < http://www.ies.ufpb.br/ojs/index.php/ies/article/view/12224/8586>. Acesso em: 28 jun. 2017.

SANTOS, H. M.; FLORES, D. Políticas de preservação digital para documentos arquivísticos. Perspectivas em Ciência da Informação, [S.I.], v. 20, n. 4, p. 197-217, dez. 2015. Disponível em: $<$ http://portaldeperiodicos.eci.ufmg.br/index.php/pci/article/view/2542/1678>. Acesso em: 17 ago. 2017. 
TIBBO, H. R.; LEE, C. A. Closing the digital curation gap: a grounded framework for providing guidance and education in digital curation. Archiving, [S. I], p. 57-62, 2012. Disponível em: Disponível em < https://ils.unc.edu/callee/p57-tibbo.pdf>. Acesso em:18 ago. 2017.

THOMAZ, K. P.; SOARES, A. J. A preservação digital e o modelo de referência Open Archival Information System (OAIS). 2004. Disponível em: <http://basessibi.c3sl.ufpr.br/brapci/index.php/article/view/0000007749/6f3e125 671cfe45b7fddce5de6cf37f8>. Acesso em: 17 ago. 2017.

UNESCO. División de la Sociedad de la Información. Directrices para la preservación del patrimonio digital. Preparado por la Biblioteca Nacional de Australia. Canberra: Biblioteca Nacional de Austrália, 2002. 176p. Disponível em: <http://unesdoc.unesco.org/images/0013/001300/130071s.pdf>. Acesso em16 ago. 2017.

UNIVERSIDADE DO PORTO. Observatório de Ciência da Informação da Universidade do Porto. Disponível em: < https://paginas.fe.up.pt/ /ci/index.php/ociup> Acesso em: 17 ago. 2017.

WEITZEL, S. da R; MESQUITA, M. A. A. de. Preservação digital em repositórios institucionais: práticas na região Sudeste do Brasil. Liinc em Revista, Rio de Janeiro, v.11, n.1, p. 181-196, maio 2015. Disponível em:<http://revista.ibict.br/liinc/index.php/liinc/article/view/778/536> Acesso em: 28 jun. 2017.

YAMAOKA, E. J. Ontologia para mapeamento da dependência tecnológica de objetos digitais no contexto da curadoria e preservação digital. AtoZ: novas práticas em informação e conhecimento, Curitiba, v. 1, n. 2, p. 6578, jan./dez. 2012. Disponível em:< http://revistas.ufpr.br/atoz/article/view/41313/> Acesso em: 28 jun. 2017.

\section{Title}

Digital Curation: Archivist's roles and responsibilities

\section{Abstract:}

Introduction: This article shows the roles and responsibilities of the archivist in the context of Digital Curation, verifying how the professional from the use of theories, technologies, instruments, processes and policies, can act and outline strategic actions and procedures for curatorship and preservation processes digital.

Objective: To investigate the roles and responsibilities of professionals in the context of digital curatorship for data preservation or digital preservation,

Methodology: Review of the literature on the professional archivist, their functions and activities in organizations in the context of digital curation.

Results: Considering the need for the archivist to act and policies on digital documents and their long-term preservation. In search of expanding and maturing theoretical and practical conceptions about the issue. The archivist with an accurate look seeks to 
modify ideas, thoughts and theories about the management of preservation and the magnification of its importance, especially the guard and the future access of digital documents. Therefore, the importance of the incorporation of qualified and prepared professionals to the corporate staff of the institutions, which can provide strategic preservation actions.

Conclusions: It concludes that the perspectives of the archivist's performance are possible in the performance of the digital curatorship. According to the existence of new researches and teachings. The training contemplates theoretical aspects, practical, technical and management being necessary to investigate about the digital curation. Reflect deeply on your training as your work in the labor market and persuasive in your doing both digital and physical Archival.

Keywords: Archivist. Digital Curation. Digital preservation. Digital document. Curator of information.

\section{Titulo}

Curatoria Digital: Papeles y responsabilidades del archivista

\section{Resumen:}

Introducción: En este artículo se muestran los papeles y responsabilidades del archivista en el contexto de la curatoria digital verificando cómo el profesional a partir del uso de teorías, de las tecnologías, instrumentos, procesos y políticas, puede actuar y delinear acciones y procedimientos estratégicos para los procesos de curaduría y preservación digital.

Objetivo: Investigar qué papeles y responsabilidades de los profesionales en el contexto de la curaduría digital para la preservación de datos o preservación digital,

Metodología: Revisión de literatura sobre el profesional archivista, sus funciones y actividades en las organizaciones.

Resultados: Considerando la necesidad de actuación del archivista y políticas sobre los documentos digitales y su preservación a largo plazo. En busca de ampliar y madurar concepciones teóricas y prácticas acerca de la cuestión. El archivista con la mirada acorde busca modificar ideas, pensamientos y teorías sobre la gestión de la preservación y la ampliación de su importancia, principalmente la custodia y el acceso futuro de los documentos digitales. Por eso la importancia de la incorporación de profesionales calificados y preparados a los cuadros corporales de las instituciones, en que puede proporcionar a las acciones estratégicas de preservación.

Conclusiones: Concluye que las perspectivas de actuación del archivista son posibles en el desempeño de la curatoria digital. De acuerdo con la existencia de nuevas investigaciones y enseñanzas. La formación comtempla aspectos teóricos, prácticos, técnico y de gestión, siendo necesario investigar sobre la curaduría digital. Reflexionar profundamente sobre su formación como su actuación en el mercado de trabajo y persuasivo en su hacer Archivística tanto digital como físico.

Palabras clave: Archivista. Curatoria digital. Preservación digital. Documento digital. Curador de la información.

Recebido: 10.03.2017

Aceito: 10.11 .2017 